\title{
PERAN KUALITAS KEHIDUPAN KERJA, WORK-FAMILY CONFLICT, DAN PERSEPSI PELUANG KERJA TERHADAP INTENSI PINDAH KERJA
}

\author{
Yohanes Ari Setiawan \\ Fakultas Sistem Informasi, STMIK Harvest Kuwera \\ Jl. Gunung Rinjani No.6 Taman Himalaya, Lippo Village Karawaci, Tangerang 15811 \\ E-mail: y.ari.setiawan@gmail.com
}

\begin{abstract}
ABSTRAK
PT. X mengalami penurunan target penjualan yang salah satunya disebabkan oleh tingginya tingkat turnover pada karyawan mereka dalam kurun waktu tiga tahun. Hasil exit interview PT. X menunjukkan bahwa alasan-alasan mereka yang keluar meliputi tidak cocok dengan atasan, administrasi perusahaan yang terlalu rumit dan bertele-tele, dukungan organisasi yang kurang dari perusahaan, kurangnya keamanan dan keuntungan yang didapat di perusahaan, peran ganda antara keluarga kerja, serta adanya peluang karier di luar PT. X. Alasan tersebut termasuk ke dalam dimensi kualitas kehidupan kerja, work-family conflict, dan persepsi peluang kerja. Berdasarkan hal tersebut, peneliti menganalisis peran kualitas kehidupan kerja, work-family conflict, dan persepsi peluang kerja terhadap intensi pindah kerja. Metode yang digunakan dalam penelitian ini adalah kuantitatif deskriptif dengan total populasi 62 karyawan PT. X. Data dianalisis dengan menggunakan regresi linear ganda. Hasil penelitian menunjukkan bahwa terdapat peran kualitas kehidupan kerja dengan nilai $\mathrm{R}^{2}=0,297(\mathrm{p}<0,05)$, peran work-family conflict dengan nilai $\mathrm{R}^{2}=0,138(\mathrm{p}<$ $0,05)$, dan persepsi peluang kerja dengan nilai $\mathrm{R}^{2}=0,233(\mathrm{p}<0,05)$ terhadap intensi pindah kerja. Diperolehnya nilai $\mathrm{F}=12,411(\mathrm{p}<0,05)$ dan nilai $\mathrm{R}^{2}=0,391$ menunjukkan bahwa terdapat peran kualitas kehidupan kerja, work-family conflict, dan persepsi peluang kerja terhadap intensi pindah kerja karyawan PT. X dengan kontribusi sebesar 39,1\%. Dengan demikian, ketiga variabel tersebut secara bersama-sama memengaruhi intensi pindah kerja karyawan PT. X.
\end{abstract}

Kata kunci: kualitas kehidupan kerja; work-family conflict; persepsi peluang kerja; intensi pindah kerja.

\section{THE ROLE OF QUALITY OF WORK LIFE, WORK-FAMILY CONFLICT, AND PERCEPTIONS OF JOB OPPORTUNITIES OF THE INTENTION TO LEAVE}

\begin{abstract}
PT. X experienced a decrease in sales target, one of which was due to the high turnover that occurred in those three years. The results of the exit interview of PT. X indicated that the reasons include not getting along with their superiors, company's complicated and wordy administration, lack of organizational support from the company, lack of security and benefits in the company, dual roles between work and families, and the existence of career opportunities outside PT. X. These reasons are included in the dimensions of quality of work life, work-family conflict, and perceptions of job opportunities. Based on this, thes researchers analyze the role of quality of work life, workfamily conflict, and perception of job opportunities on the intention to change jobs. The method used in this study is descriptive-quantitative with a total population of 62 PT. X. employees. The data was analyzed using multiple linear regression. The results showed that there is a role of quality of work life with a value of $R^{2}=0,297(p<0,05)$, the role of work-family conflict with a value of $R^{2}=0,138(p<0,05)$, and the perception of job opportunities with a value of $R^{2}=0,233$ with $(p<0,05)$ on the intention to leave work. F-value of $12,411(p<0,05)$ and $R^{2}$-value of 0,391 showed that there is a role of quality of work life, work-family conflict, and perception of job opportunities on the intention to leave work with a contribution of $39,1 \%$ on PT. X employees. Thus, the three variables together affect the intention to changes jobs of employees of PT. X
\end{abstract}

Keywords: quality of work life; work-family conflict; perception of job opportunities; intention to leave work. 


\section{PENDAHULUAN}

Persaingan dalam perubahan-perubahan ekonomi pada era globalisasi ini membawa dampak yang cukup besar bagi dunia bisnis di Indonesia. Hal ini pun terjadi pada PT. X yang bergerak pada bidang konstruksi. Perusahaan yang telah berusia 33 tahun ini merupakan perusahaan yang sudah cukup lama menggeluti dunia bisnis konstruksi. Pada masa awal berdirinya, perusahaan ini hanya memiliki tiga orang karyawan, yang kemudian meningkat hingga sekarang mencapai tujuh puluh orang karyawan. Sayangnya, bertambahnya karyawan tidak diimbangi dengan penjualan yang mencapai target dalam tiga tahun terakhir Penurunan penjualan disebabkan oleh peningkatan turnover pada tiga tahun terakhir Data tersebut peneliti dapatkan dari hasil interview dengan HRD manager PT. X.

Pengunduran diri karyawan yang meningkat setiap tahunnya dapat menimbulkan masalah dan memberikan konsekuensi negative terhadap organisasi, salah satunya adalah biaya kerugian yang harus ditanggung perusahaan (Slavianska, 2012). Menurut Kurnia (2010) dalam Pratiwi \& Riyono (2017), kerugian lain dari pengunduran diri karyawan adalah perilaku kontraproduktif karyawan dalam bekerja. Karyawan yang mengundurkan diri akan diawali dengan niat pindah kerja. Tindakan mengundurkan diri ini dapat diprediksi melalui variabel intensi pindah kerja. Mowday, Porter, \& Steer (1982) dalam Giffen (2015) mendefinisikan intensi pindah kerja sebagai kesadaran individu atau karyawan untuk berhenti dari perusahaan dalam waktu dekat, dan merupakan prediktor yang kuat terhadap turnover. Menurut Griffeth, Hom \& Gaertner (2000) dalam Alony, Hasan, \& Sense (2014), tiga faktor utama karyawan memutuskan untuk meninggalkan organisasi adalah ketidakpuasan kerja atau organisasi, peluang kerja atau karier alternatif, dan keputusan pribadi untuk pindah dari organisasi.

Terdapat berbagai macam alasan karyawan mengundurkan diri yang mereka ungkapkan melalui exit interview. Peneliti menggunakan rekap hasil exit interview PT. X selama tiga tahun terakhir dikarenakan terjadi peningkatan angka turnover selama tiga tahun terakhir pada perusahaan tersebut. Berdasarkan hasil rekap exit interview, ada tiga faktor yang menyebabkan turnover, yaitu faktor organisasi, faktor individu, dan faktor eksternal. Salah satu hasil rekap exit interview karyawan PT. X adalah tidak cocok dengan atasan, administrasi perusahaan yang terlalu rumit dan bertele-tele, dukungan organisasi yang kurang dari perusahaan, serta kurangnya keamanan dan keuntungan yang didapat di perusahaan.

Beberapa alasan yang disampaikan karyawan PT. X tersebut termasuk dalam dimensi kualitas kehidupan kerja. Walton (1973) dalam Swamy, Nanjundeswarawarmy, \& Rashmi (2015) mengungkapkan bahwa terdapat delapan dimensi kualitas kehidupan kerja, yaitu: 1) adequate and fair compensation; 2) safe and healthy working conditions; 3) immediate opportunity to use and develop human capacities; 4) opportunity for career growth; 5) social integration in the work organization; 6) constitutionalism in the work organization; 7) work and total life space, dan; 8) social relevance of work life. Berdasarkan rekap exit interview, terdapat beberapa alasan yang termasuk dalam dimensi kualitas kehidupan kerja yaitu adequate and fair compensation, social integration in the work organization, dan constitutionalism in the work organization. Tiga dimensi ini memengaruhi alasan karyawan keluar dalam tiga tahun terakhir. Walton (1973) dalam Swamy, Nanjundeswarawarmy, \& Rashmi (2015) menyebutkan bahwa ketidakpuasan terhadap kehidupan kerja merupakan masalah yang akan berpengaruh bagi hampir seluruh pekerja di satu waktu, atau lain waktu berkaitan dengan posisi atau status, rasa frustasi, kebosanan, maupun kemarahan. Hal ini merupakan sesuatu yang sering terjadi pada karyawan yang kurang puas dengan kehidupan kerja.

Kualitas kehidupan kerja diketahui merupakan salah satu faktor dari turnover. Wiligamage \& Karunanayake (2016) melakukan penelitian yang melibatkan 350 karyawan operator mesin jahit di Sri Lanka dan diperoleh hasil bahwa kualitas kehidupan kerja berhubungan negatif secara signifikan terhadap turnover intention. Penelitian yang dilakukan Kumar dan Thomas (2016) terhadap 261 karyawan rumah sakit swasta pun menunjukkan bahwa kualitas kehidupan kerja berhubungan negatif dengan turnover intention karyawan, dan diketahui adanya beberapa prediktor turnover intention yang terdiri dari motivasi rendah, kebijakan organisasi, komunikasi yang buruk, tekanan kerja, dan kurangnya keamanan kerja. Penelitian-penelitian tersebut menunjukkan bahwa makin rendah kualitas kehidupan kerja seseorang, maka intensi seseorag untuk keluar kerja akan meningkat. 
Faktor kedua dari turnover adalah faktor individu. Berdasarkan hasil rekap exit interview, sebagian besar karyawan yang mengundurkan diri memiliki alasan untuk meninggalkan pekerjaan mereka karena ingin fokus untuk mengurusi keluarga. Hal ini karena tidak adanya keseimbangan peran antara pekerjaan dan keluarga yang mereka jalani sehingga harus memilih salah satu dan tidak bisa menjalankan keduanya. Greenhaus \& Beutell (1985) dalam Wulandari \& Adnyani (2016) mengungkapkan bahwa konflik yang terjadi pada individu akibat menanggung peran ganda, baik dalam pekerjaan (work) maupun keluarga (family), disebut dengan work-family conflict. Kecenderungan ini terjadi karena jam kerja dan beban pekerjaan terlalu padat sehingga hanya berfokus pada satu peran saja. Konflik ini bisa terjadi bagi pria maupun wanita, tetapi lebih cenderung untuk terjadi pada wanita yang sudah menikah dan memiliki anak.

Karyawan PT. X yang mengundurkan diri dikarenakan alasan keluarga sebagian besar adalah wanita. Pembagian peran antara keluarga dan pekerjaan menjadi sebuah masalah yang dihadapi oleh karyawan wanita, sehingga pada kenyataannya banyak wanita yang tidak cukup mampu untuk mengatasi permasalahan ini. Primastuti (2000) dalam Wulandari \& Adnyani (2016) mengungkapkan bahwa kebanyakan peranan ganda ini dilakukan untuk mendapatkan penghasilan dan kepuasan kerja sehingga terdapat kemunculan konflik dalam menjalani kedua peran ini. Konflik ini menyebabkan adanya tuntutan pada sisi keluarga maupun pekerjaan, yang kemudian memicu terjadinya work-family conflict.

Afsar \& Rehman (2017) meneliti 187 perawat yang bekerja di rumah sakit di Islamabad menunjukkan hasil bahwa adanya hubungan positif antara work-family conflict terhadap turnover intention. Sejalan dengan penelitian tersebut, penelitian Nisa dan Malik (2016) terhadap 300 tenaga medis di perusahaan swasta juga menunjukkan bahwa work-family conflict berpengaruh terhadap turnover intention. Sebanyak 3.563 dokter di Tiongkok yang menjadi subjek penelitian Lu et al. (2018) pun menyebutkan adanya hubungan positif antara work-family conflict terhadap turnover intention pada dokter tersebut. Penelitian-penelitian tersebut menunjukkan bahwa makin tinggi work-family conflict suatu individu, maka makin tinggi pula tingkat turnover intention pada individu yang bersangkutan, dan begitu pula sebaliknya.

Adanya peluang kerja di luar perusahaan menjadi faktor ketiga dari turnover. Berdasarkan rekap exit interview, alasan lain karyawan mengundurkan diri dikarenakan karyawan melihat peluang yang lebih baik diluar perusahaan. Karyawan menyebutkan di tempat lain lebih baik dari segi gaji, tunjangan, jarak, dan kesempatan promosi yang lebih baik dibandingkan PT. X. Victoria, Zamralita, \& Saraswati (2017) meneliti tiga ratus karyawan pada perusahaan swasta, dan hasil penelitiannya menyatakan bahwa terdapat hubungan positif antara persepsi peluang kerja dengan intensi keluar kerja karyawan.

Berdasarkan uraian di atas, maka dapat diketahui bahwa alasan karyawan mengundurkan diri disebabkan oleh berbagai faktor. Meningkatnya turnover selama tiga tahun terakhir menjadi salah satu penyebab turunnya penjualan PT. X. Oleh karena itu, peneliti melakukan penelitian kepada karyawan yang masih aktif sebagai upaya pencegahan lebih lanjut. Pada penelitian ini, peneliti ingin mengetahui peran kualitas kehidupan kerja, work-family conflict, dan persepsi peluang kerja terhadap intensi pindah kerja.

\section{METODE}

Penelitian dilakukan pada seluruh karyawan aktif di PT. X. Peneliti membuat kuesioner yang dibagikan kepada 70 karyawan menggunakan Google Form dan hanya 62 partisipan yang mengisi. Delapan orang lainya tidak mengembalikan kuesioner dalam waktu yang ditentukan. Penelitian ini menggunakan metode penelitian kuantitatif dan noneksperimental. Variabel dependen dari penelitian ini adalah intensi pindah kerja, dengan variabel independen yang meliputi kualitas kehidupan kerja, work-family conflict, dan persepsi peluang kerja.

Peneliti menggunakan alat ukur Turnover Intention Scale (Cohen, 1999) yang telah diadaptasi dan diterjemahkan ke dalam Bahasa Indonesia oleh Rostiana, Zamralita, \& Suyasa (2014) dari bagian riset dan pengukuran Fakultas Psikologi Universitas Tarumanagara untuk mengukur intensi pindah kerja. Alat ukur ini terdiri dari sepuluh butir pernyataan, terdiri dari enam butir pernyataan positif dan empat butir pernyataan negatif.

Alat ukur ini menggunakan skala Likert dengan empat pilihan jawaban, yaitu STS (sangat tidak setuju), TS (tidak setuju), S (setuju), dan SS (sangat setuju). Skor untuk jawaban dari butir positif adalah 
$\mathrm{TS}=3, \mathrm{~S}=2$, dan $\mathrm{SS}=1$. Subjek dapat memberikan persetujuan terhadap pernyataan dengan memilih salah satu dari pilihan yang tersedia. Definisi operasional dari intensi pindah kerja adalah semakin tinggi skor dari skala intensi pindah kerja, maka semakin tinggi pula keinginan seseorang untuk keluar dari pekerjaan tempatnya bekerja saat ini secara sukarela. Peneliti melakukan uji reliabilitas dan diperoleh koefisien alpha Cronbach sebesar 0,911. Peneliti juga melakukan uji validitas pada alat ukur intensi pindah kerja, dan hasilnya menunjukkan bahwa item-item pada alat ukur ini adalah valid dengan nilai correcteditem total di atas 0,200 pada setiap butirnya. Hasil tersebut menunjukkan tidak adanya butir yang digugurkan sehingga seluruh butir dapat digunakan untuk pengolahan data.

Alat ukur lainnya yang peneliti gunakan adalah alat ukur kualitas kehidupan kerja yang mengacu pada delapan dimensi kualitas kehidupan kerja menurut Walton (1973) dan dua dimensi dari Hackman \& Oldham (Rostiana, Zamralita, \& Suyasa, 2014). Dengan demikian, alat ukur ini meliputi sepuluh dimensi yang terdiri dari job characteristic, coworker, personal development, promotion, social relevant of employee, supervisory, work balance, work culture, work condition, dan pay benefit.

Dimensi job characteristic diukur dengan menggunakan tujuh item. Makin tinggi skor kualitas kehidupan kerja pada dimensi job characteristic, maka makin jelas tanggung jawab pekerjaan dan sistem penilaian dalam pekerjaan yang diberikan oleh atasan. Peneliti melakukan uji reliabilitas dan diperoleh koefisiean alpha Cronbach sebesar 0,824. Peneliti juga melakukan uji validitas pada dimensi job characteristic dan hasilnya menunjukkan bahwa item-item pada alat ukur ini adalah valid dengan nilai corrected-item total di atas 0,200 pada setiap butirnya. Hasil ini menunjukkan bahwa tidak adanya butir yang digugurkan sehingga seluruh butir dapat digunakan untuk pengolahan data.

Dimensi coworker diukur dengan menggunakan tiga butir item. Skor kualitas kehidupan kerja yang tinggi pada dimensi coworker menggambarkan kelompok kerja yang saling mendukung, adanya rasa kebersamaan dalam kelompok, dan adanya perasaan terbuka antarkaryawan. Peneliti melakukan uji reliabilitas dan diperoleh koefisiean alpha Cronbach sebesar 0,877 . Peneliti juga melakukan uji validitas pada dimensi coworker dan hasilnya menunjukkan bahwa item-item pada alat ukur ini adalah valid dengan nilai corrected-item total di atas 0,200 pada setiap butirnya. Hasil ini menunjukkan tidak adanya butir yang digugurkan sehingga seluruh butir dapat digunakan untuk pengolahan data.

Dimensi personal development diukur dengan menggunakan empat butir item. Makin tinggi skor kualitas kehidupan kerja pada dimensi personal development, maka makin tinggi kesempatan yang diberikan pada karyawan untuk tumbuh dan berkembang dengan menggunakan dan mengembangkan segala keterampilan dan kemampuan yang karyawan miliki melalui kesempatan mengikuti pelatihan dan melanjutkan pendidikan. Peneliti melakukan uji reliabilitas dan diperoleh koefisiean alpha Cronbach sebesar 0,809. Peneliti juga melakukan uji validitas pada dimensi personal development dan hasilnya menunjukkan bahwa item-item pada alat ukur ini adalah valid dengan nilai corrected-item total di atas 0,200 pada setiap butirnya. Hasil ini menunjukkan bahwa tidak adanya butir yang digugurkan sehingga seluruh butir dapat digunakan untuk pengolahan data.

Dimensi promotion diukur dengan menggunakan tiga butir item. Makin tinggi skor kualitas kehidupan kerja pada dimensi promotion, maka makin adanya kejelasan tentang peluang bagi diri karyawan untuk memiliki jenjang karier yang lebih baik. Peneliti melakukan uji reliabilitas dan diperoleh koefisiean alpha Cronbach sebesar 0,792. Peneliti juga melakukan uji validitas pada dimensi promotion dan hasilnya menunjukkan bahwa item-item pada alat ukur ini adalah valid dengan nilai corrected-item total di atas 0,200 pada setiap butirnya. Hasil ini menunjukkan tidak adanya butir yang digugurkan sehingga seluruh butir dapat digunakan untuk pengolahan data.

Dimensi social relevant of employee diukur dengan menggunakan lima butir item. Makin tinggi skor kualitas kehidupan kerja pada dimensi social relevant of employee, maka makin tinggi keterlibatan organisasi terhadap lingkungannya sehingga karyawan memiliki rasa bangga akan organisasinya. Peneliti melakukan uji reliabilitas dan diperoleh koefisiean alpha Cronbach sebesar 0,684. Peneliti juga melakukan uji validitas pada dimensi social relevant of employee dan hasilnya menunjukkan bahwa item-item pada alat ukur ini adalah valid dengan nilai corrected-item total di atas 0,200 pada setiap butirnya. Hasil ini menunjukkan tidak adanya butir yang digugurkan sehingga seluruh butir dapat digunakan untuk pengolahan data.

Dimensi supervisory diukur dengan menggunakan lima butir item. Skor kualitas kehidupan kerja yang tinggi pada dimensi supervisory menunjukkan bahwa karyawan melihat atasannya sebagai seorang 
teladan yang dapat mengarahkan bawahannya. Peneliti melakukan uji reliabilitas dan diperoleh koefisiean alpha Cronbach sebesar 0,888. Peneliti juga melakukan uji validitas pada dimensi supervisory dan hasilnya menunjukkan bahwa item-item pada alat ukur ini adalah valid dengan nilai corrected-item total di atas 0,200 pada setiap butirnya. Hasil ini menunjukkan tidak adanya butir yang digugurkan sehingga seluruh butir dapat digunakan untuk pengolahan data.

Dimensi work balance diukur dengan menggunakan empat butir item. Makin tinggi skor kualitas kehidupan kerja pada dimensi work balance, maka semakin tinggi keseimbangan dalam hal jam kerja, permintaan karir, waktu berlibur, serta waktu untuk keluarga. Peneliti melakukan uji reliabilitas dan diperoleh koefisiean alpha Cronbach sebesar 0,696. Peneliti juga melakukan uji validitas pada dimensi work balance dan hasilnya menunjukkan bahwa item-item pada alat ukur ini adalah valid dengan nilai corrected-item total di atas 0,200 pada setiap butirnya. Hasil ini menunjukkan tidak adanya butir yang digugurkan sehingga seluruh butir dapat digunakan untuk pengolahan data.

Dimensi work culture diukur dengan menggunakan delapan butir item. Makin tinggi skor kualitas kehidupan kerja pada dimensi work culture, maka makin tinggi nilai (budaya) keteraturan atau kedisiplinan dalam bekerja. Peneliti melakukan uji reliabilitas dan diperoleh koefisiean alpha Cronbach sebesar 0,826. Peneliti juga melakukan uji validitas pada dimensi work culture dan hasilnya menunjukkan bahwa itemitem pada alat ukur ini adalah valid dengan nilai corrected-item total di atas 0,200 pada setiap butirnya. Hasil ini menunjukkan tidak adanya butir yang digugurkan sehingga seluruh butir dapat digunakan untuk pengolahan data.

Dimensi work condition diukur dengan menggunakan tiga butir item. Skor kualitas kehidupan kerja yang tinggi pada dimensi work condition menunjukkan ketersediaan lingkungan kerja yang dirasa sehat dan aman yang dapat meminimalisasi risiko penyakit, serta bebas dari kebisingan, gangguan pandangan seperti pencahayaan, dan polusi. Peneliti melakukan uji reliabilitas dan diperoleh koefisiean alpha Cronbach sebesar 0,616 . Peneliti juga melakukan uji validitas pada dimensi work condition dan hasilnya menunjukkan bahwa item-item pada alat ukur ini adalah valid dengan nilai corrected-item total di atas 0,200 pada setiap butirnya. Hasil ini menunjukkan tidak adanya butir yang digugurkan sehingga seluruh butir dapat digunakan untuk pengolahan data.

Dimensi pay benefit diukur dengan menggunakan lima butir item. Skor kualitas kehidupan kerja yang tinggi pada dimensi pay benefit menggambarkan adanya kesesuaian antara gaji dengan standar sosial yang berkecukupan atau standar subjektif dari penerima. Peneliti melakukan uji reliabilitas dan diperoleh koefisiean alpha Cronbach sebesar 0,788. Peneliti juga melakukan uji validitas pada dimensi pay benefit dan hasilnya menunjukkan bahwa item-item pada alat ukur ini adalah valid dengan nilai corrected-item total di atas 0,200 pada setiap butirnya. Hasil ini menunjukkan tidak adanya butir yang digugurkan sehingga seluruh butir dapat digunakan untuk pengolahan data.

Penulis menggunakan alat ukur milik Carlson, Kacmar, \& Williams (2000) yang telah diadaptasi dan diterjemahkan ke dalam Bahasa Indonesia oleh Rostiana, Zamralita, \& Suyasa (2016) dari bagian riset dan pengukuran Fakultas Psikologi Universitas Tarumanagara untuk mengukur work family conflict. Alat ukur ini terdiri dari delapan belas pernyataan dengan tiga dimensi, yaitu time, strain, dan behavior. Alat ukur ini menggunakan skala Likert dengan empat pilihan jawaban, yaitu Sangat Buruk, Buruk, Baik, dan Sangat Baik. Skor untuk jawaban dari setiap butir positif adalah Sangat Buruk $=1$, Buruk $=2$, Baik $=3$, dan Sangat Baik $=4$. Subjek dapat memberikan persetujuan terhadap pernyataan dengan memilih salah satu dari pilihan yang tersedia.

Dimensi time diukur dengan menggunakan enam butir item. Skor tinggi dari dimensi time menggambarkan ketidakmampuan seseorang dalam mengatur waktu ketika terdapat konflik peran antara keluarga dan pekerjaan. Peneliti melakukan uji reliabilitas dan diperoleh koefisiean alpha Cronbach sebesar 0,836 . Peneliti juga melakukan uji validitas pada dimensi time dan hasilnya menunjukkan bahwa item-item pada alat ukur ini adalah valid dengan nilai corrected-item total di atas 0,200 pada setiap butirnya. Hasil ini menunjukkan tidak adanya butir yang digugurkan sehingga seluruh butir dapat digunakan untuk pengolahan data.

Dimensi strain diukur dengan menggunakan enam butir item. Skor tinggi dari skala dimensi strain menggambarkan ketidakmampuan seseorang dalam mengatur tekanan ketika terdapat konflik peran antara keluarga dan pekerjaan. Peneliti melakukan uji reliabilitas dan diperoleh koefisiean alpha Cronbach sebesar 0,861 . Peneliti juga melakukan uji validitas pada dimensi strain dan hasilnya menunjukkan bahwa 
item-item pada alat ukur ini adalah valid dengan nilai corrected-item total di atas 0,200 pada setiap butirnya. Hasil ini menunjukkan tidak adanya butir yang digugurkan sehingga seluruh butir dapat digunakan untuk pengolahan data.

Dimensi behavior diukur dengan menggunakan enam butir item. Skor tinggi dari skala dimensi behavior menggambarkan ketidakmampuan seseorang dalam mengatur perilaku ketika terdapat konflik peran antara keluarga dan pekerjaan. Peneliti melakukan uji reliabilitas dan diperoleh koefisiean alpha Cronbach sebesar 0,926. Peneliti juga melakukan uji validitas pada dimensi behavior dan hasilnya menunjukkan bahwa item-item pada alat ukur ini adalah valid dengan nilai corrected-item total di atas 0,200 pada setiap butirnya. Hasil ini menunjukkan tidak adanya butir yang digugurkan sehingga seluruh butir dapat digunakan untuk pengolahan data.

Alat ukur lainnya yang peneliti gunakan adalah alat ukur persepsi peluang kerja yang dikembangkan oleh Putri (2016) dalam Victoria, Zamralita, dan Saraswati (2017). Alat ukur ini terdiri dari sepuluh butir pernyataan dengan unidimensi, yang meliputi tujuh butir pernyataan positif dan tiga butir pernyataan negatif. Alat ukur persepsi peluang kerja menggunakan skala Likert dengan empat pilihan jawaban, yaitu STS (sangat tidak setuju), TS (tidak setuju), S (setuju), dan SS (sangat setuju). Skor untuk jawaban dari butir positif, yakni $\mathrm{STS}=1, \mathrm{TS}=2, \mathrm{~S}=3$, dan $\mathrm{SS}=4$, sedangkan skor untuk jawaban dari butir negatif yaitu $\mathrm{STS}=4, \mathrm{TS}=3, \mathrm{~S}=2$, dan $\mathrm{SS}=1$. Subjek dapat memberikan persetujuan terhadap pernyataan dengan memilih salah satu dari pilihan yang tersedia. Definisi operasional dari persepsi peluang kerja adalah makin tinggi skor dari skala persepsi peluang kerja, maka semakin tinggi perasaan seseorang dalam memiliki peluang kerja di luar pekerjaannya saat ini.

Peneliti melakukan uji reliabilitas dan diperoleh koefisien alpha Cronbach sebesar 0,883. Peneliti juga melakukan uji validitas pada alat ukur ini, dan hasilnya menunjukkan bahwa item-item pada alat ukur intensi pindah kerja adalah valid dengan nilai corrected item-total pada setiap butirnya berada di atas 0,200. Hasil ini menunjukkan tidak adanya butir yang digugurkan sehingga seluruh butir dapat digunakan untuk pengolahan data.

Pengolahan data dalam penelitian ini akan dilakukan menggunakan program SPSS (Statistical Product and Service Solutions) versi 20.0. Peneliti menggunakan program tersebut untuk melakukan uji validitas dan uji reliabilitas alat ukur dari setiap variabel. Sebelum melakukan uji hipotesis, peneliti juga melakukan pengujian terhadap asumsi-asumsi regresi linear dengan pengujian asumsi klasik berupa uji normalitas, uji multikoliniearitas, dan uji heteroskedastisitas.

\section{HASIL DAN PEMBAHASAN}

Penelitian ini memiliki empat variabel, yaitu: 1) intensi keluar kerja sebagai variabel dependen; 2) kualitas kehidupan kerja sebagai variabel independen; 3) work-family conflict sebagai variabel independen, dan; 4) persepsi peluang kerja sebagai variabel independen. Sebelum melakukan pengujian hipotesis, peneliti melakukan uji normalitas data untuk mengetahui penyebaran data partisipan dalam penelitian ini. Uji normalitas dilakukan untuk setiap variabel penelitian, yaitu intensi pindah kerja, kualitas kehidupan kerja, work-family conflict, dan persepsi peluang kerja dengan menggunakan metode analisis One-Sample Kolmogorov-Smirnov. Jika p $>0,05$, maka penyebaran data berdistribusi normal. Hasil uji normalitas dapat dilihat pada Tabel 1.

Tabel 1. Hasil Uji Normalitas

\begin{tabular}{lcccc}
\hline \multicolumn{1}{c}{ Variabel } & \multicolumn{2}{c}{ Kolmogorov-Smirnov } & \multicolumn{2}{c}{ Shapiro-Wilk } \\
& Statistic & Sig. & Statistic & Sig. \\
\hline Intensi pindah kerja & 0,120 & 0,028 & 0,950 & 0,013 \\
Kualitas kehidupan kerja & 0,105 & 0,086 & 0,977 & 0,296 \\
Work-family conflict & 0,081 & 0,200 & 0,967 & 0,091 \\
Persepsi peluang kerja & 0,146 & 0,002 & 0,949 & 0,012 \\
\hline
\end{tabular}


Berdasarkan Tabel 1, variabel persepsi peluang kerja tidak memenuhi persyaratan uji normalitas secara metode One Sample Kolmogorov-Smirnov dan Shapiro-Wilk. Variabel ini menggunakan hasil sebaran QQ plot. Hasil QQ plot persepsi peluang kerja disajikan pada Gambar 1.

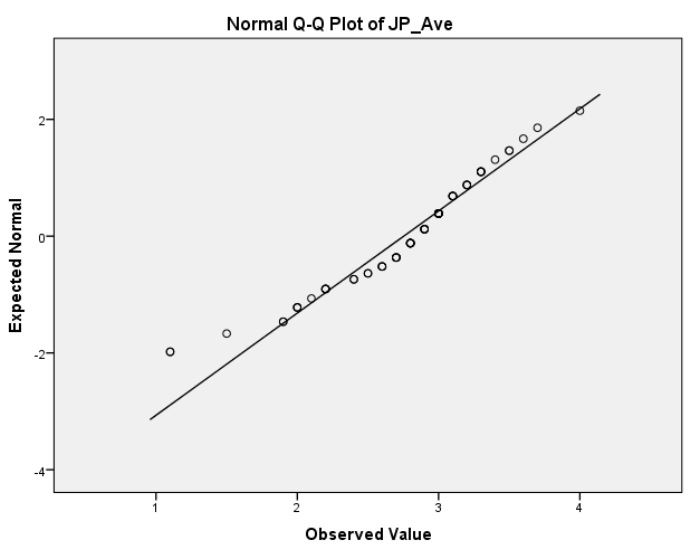

Gambar 1. Hasil Uji Normalitas Persepsi Peluang Kerja

Peneliti juga melakukan uji multikolinieritas yang bertujuan untuk mengetahui ada atau tidaknya korelasi antarvariabel independen dengan variabel dependen. Cara untuk melihat ada atau tidaknya masalah pada uji multikolinieritas adalah dengan melihat nilai tolerance dan variance inflation factor (VIF). Nilai yang disarankan adalah nilai tolerance lebih besar dari 0,10 dan nilai VIF lebih kecil dari 10. Informasi tentang hasil pengujian multikolinieritas dapat dilihat pada Tabel 2.

Tabel 2. Hasil Uji Multikolinieritas

\begin{tabular}{lcc}
\hline \multicolumn{1}{c}{ Variabel } & Nilai Tolerance & Nilai VIF \\
\hline Kualitas kehidupan kerja & 0,567 & 1,762 \\
Work-family conflict & 0,955 & 1,048 \\
Persepsi peluang kerja & 0,572 & 1,747 \\
\hline
\end{tabular}

Berdasarkan Tabel 2, variabel kualitas kehidupan kerja, work-family conflict, dan persepsi peluang kerja memiliki nilai tolerance $>0,10$ dan nilai VIF $<10$. Oleh karena itu, dapat disimpulkan bahwa data seluruh variabel independen memenuhi uji asumsi multikolinieritas sehingga pengolahan data dapat dilanjutkan pada tahap uji regresi.

Peneliti juga melakukan uji heteroskedastisitas yang bertujuan untuk mengetahui variance dan data residu berbeda dan tetap. Apabila variance sama, maka data bersifat homoskedastisitas, dan jika berbeda, maka bersifat heteroskedastisitas. Hasil uji heteroskedastisitas dapat dilihat pada Gambar 2.

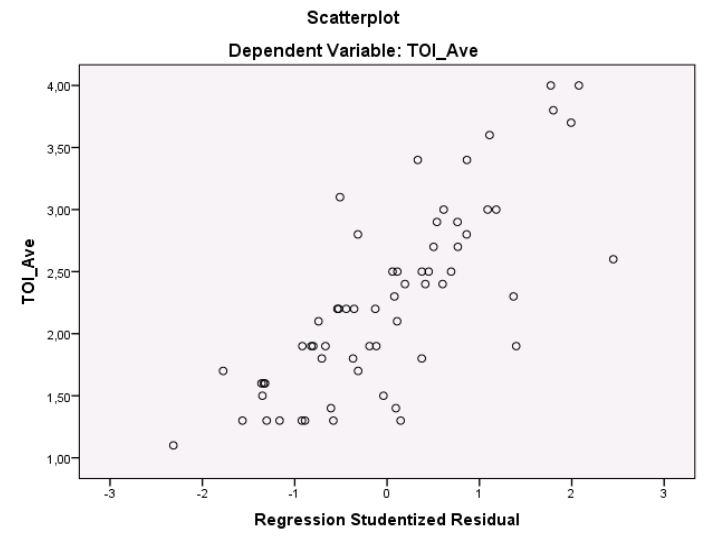

Gambar 2. Hasil Uji Heteroskedastisitas 
Berdasarkan Gambar 2, dapat dijelaskan bahwa titik plotting menyebar secara acak dan tidak mempunyai pola yang teratur sehingga dapat dikatakan tidak terjadi masalah heteroskedastisitas.

Peneliti melakukan uji korelasi dengan bivariate (korelasi Pearson) menggunakan program SPSS untuk mengetahui hasil korelasi yang dilakukan antarvariabel serta dimensi antara variabelnya. Dari pengujian tersebut, diperoleh hasil korelasi yang signifikan antara variabel kualitas kehidupan kerja dan intensi pindah kerja, yang dapat dilihat pada Tabel 3.

Tabel 3. Gambaran Korelasi antara Kualitas Kehidupan Kerja dan Intensi Pindah Kerja

\begin{tabular}{lccc}
\hline \multicolumn{1}{c}{ Variabel } & Nilai Korelasi & Sig. (2-tailed) & Korelasi \\
\hline Kualitas kehidupan kerja - Intensi keluar kerja & $-0,545$ & 0,000 & Signifikan \\
Job characteristic - Intensi pindah kerja & $-0,589$ & 0,000 & Signifikan \\
Coworker - Intensi pindah kerja & $-0,272$ & 0,016 & Signifikan \\
Personal development - Intensi pindah kerja & $-0,483$ & 0,000 & Signifikan \\
Promotion - Intensi pindah kerja & $-0,526$ & 0,000 & Signifikan \\
Social relevant of employee - Intensi pindah kerja & $-0,307$ & 0,008 & Signifikan \\
Supervisory - Intensi pindah kerja & $-0,401$ & 0,001 & Signifikan \\
Work balance - Intensi pindah kerja & $-0,471$ & 0,000 & Signifikan \\
Work culture - Intensi pindah kerja & $-0,339$ & 0,004 & Signifikan \\
Work conditions - Intensi pindah kerja & $-0,327$ & 0,005 & Signifikan \\
Pay \& benefit - Intensi pindah kerja & $-0,380$ & 0,001 & Signifikan \\
\hline
\end{tabular}

Peneliti juga melakukan uji korelasi antara variabel dan masing-masing dimensi work-family conflict dengan variabel intensi pindah kerja. Dari pengujian tersebut, diperoleh hasil korelasi yang signifikan antara variabel work-family conflict dan intensi pindah kerja. Untuk hasil selengkapnya dapat dilihat pada Tabel 4.

Tabel 4. Gambaran Korelasi Work-Family Conflict dengan Intensi Pindah Kerja

\begin{tabular}{lccc}
\hline \multicolumn{1}{c}{ Variabel } & Nilai Korelasi & Sig. (2-tailed) & Korelasi \\
\hline Work-family conflict - Intensi pindah kerja & 0,372 & 0,001 & Signifikan \\
Time - Intensi pindah kerja & 0,283 & 0,013 & Signifikan \\
Strain - Intensi pindah kerja & 0,374 & 0,001 & Signifikan \\
Behavior - Intensi pindah kerja & 0,315 & 0,006 & Signifikan \\
\hline
\end{tabular}

Peneliti juga melakukan uji korelasi antara variabel persepsi peluang kerja dengan variabel intensi pindah kerja. Dari pengujian tersebut, diperoleh hasil korelasi yang signifikan antara variabel persepsi peluang kerja dan intensi pindah kerja, sebagaimana yang disajikan pada Tabel 5.

Tabel 5. Gambaran Korelasi Persepsi Peluang Kerja dengan Intensi Pindah Kerja

\begin{tabular}{cccc}
\hline Variabel & Nilai Korelasi & Sig. (2-tailed) & Korelasi \\
\hline Persepsi peluang kerja - Intensi pindah kerja & 0,483 & 0,000 & Signifikan \\
\hline
\end{tabular}

Uji hipotesis pertama dilakukan untuk melihat peran kualitas kehidupan kerja terhadap intensi pindah kerja. Peneliti menggunakan metode uji regresi linear sederhana. Berdasarkan perhitungan yang dilakukan, diperoleh nilai koefisien determinasi $\mathrm{R}^{2}=0,297$. Hal ini menggambarkan bahwa kualitas kehidupan kerja memberikan sumbangan sebesar 29,7\% terhadap intensi pindah kerja, sementara 70,3\% sisanya dipengaruhi oleh faktor lain. Nilai $\mathrm{F}=25,314$ dengan $\mathrm{p}<0,05$ menandakan bahwa hipotesis 1 yang menyatakan "terdapat peran kualitas kehidupan kerja terhadap intensi pindah kerja" diterima, sehingga dapat dikatakan bahwa kualitas kehidupan kerja berperan langsung terhadap intensi pindah kerja. Selain itu, kualitas kehidupan kerja juga diketahui memiliki peran negatif secara signifikan terhadap intensi pindah kerja $(\beta=-0,545, \mathrm{p}<0,05)$ Arah hubungan yang bersifat negatif menandakan bahwa makin tinggi nilai kualitas kehidupan kerja, maka makin rendah nilai intensi pindah kerja atau niat individu untuk pindah dari pekerjaan tempat bekerja saat ini, dan begitu pula sebaliknya.

Jika dilihat dari peranan dimensi kualitas kehidupan kerja terhadap intensi pindah kerja, pengaruh yang paling besar terdapat pada dimensi job characteristic dengan nilai $\mathrm{R}^{2}=0,347$ Hal ini menggambarkan 
bahwa dimensi job characteristic pada kualitas kehidupan kerja memberi pengaruh negatif sebesar 34,7\% secara signifikan terhadap intensi pindah kerja $(\beta=-0,589, \mathrm{p}<0,05)$. Dimensi yang paling kecil pengaruhnya adalah coworker dengan nilai $\mathrm{R}^{2}=0,074$. Hal ini menggambarkan bahwa dimensi coworker pada kualitas kehidupan kerja memberi pengaruh negatif sebesar 7,4\% secara signifikan terhadap intensi keluar kerja $(\beta=-0,272, p<0,05)$. Data selengkapnya dapat dilihat pada Tabel 6 .

$\underline{\text { Tabel 6. Gambaran Peran Dimensi Kualitas Kehidupan Kerja terhadap Intensi Pindah Kerja }}$

\begin{tabular}{lccccc}
\hline \multicolumn{1}{c}{ Variabel/Dimensi } & Mean & $\mathrm{R}^{2}$ & $\mathrm{~F}$ & $\beta$ & Sig. \\
\hline Job characteristic & 2,8986 & 0,347 & 31,869 & $-0,0589$ & 0,000 \\
Coworker & 3,3280 & 0,074 & 4,792 & $-0,272$ & 0,000 \\
Personal development & 2,9113 & 0,233 & 18,212 & $-0,483$ & 0,000 \\
Promotion & 2,6774 & 0,276 & 22,897 & $-0,526$ & 0,000 \\
Social relevant & 3,0097 & 0,079 & 6,224 & $-0,307$ & 0,015 \\
Supervisory & 2,9581 & 0,160 & 11,470 & $-0,401$ & 0,001 \\
Work balance & 2,8589 & 0,222 & 17,147 & $-0,471$ & 0,000 \\
Work culture & 3,1048 & 0,115 & 7,791 & $-0,339$ & 0,007 \\
Work condition & 3,1075 & 0,107 & 7,167 & $-0,327$ & 0,010 \\
Pay \& benefit & 2,7871 & 0,145 & 10,150 & $-0,380$ & 0,002 \\
\hline
\end{tabular}

Faktor organisasi, yaitu kualitas kehidupan kerja, dalam hal ini terbukti memiliki peran terhadap intensi pindah kerja. Hasil ini sejalan dengan beberapa penelitian sebelumnya. Wiligamage \& Karunanayake (2016) yang meneliti 350 karyawan di Sri Lanka melihat bahwa kualitas kehidupan kerja berhubungan negatif secara signifikan terhadap intensi pindah kerja $\left(\mathrm{R}^{2}=0,561\right.$ dan $\left.\mathrm{p}<0,001\right)$. Penelitian Kumar \& Thomas (2016) terhadap 261 karyawan rumah sakit swasta juga menunjukkan hubungan negatif yang signifikan. Mosadeghrad (2013) pun mengemukakan bahwa, berdasarkan hasil penelitiannya terhadap 296 perawat di Iran, promotion menjadi dimensi yang memiliki hubungan paling kuat dalam menentukan intensi pindah kerja dengan nilai $\mathrm{r}=0,817$.

Uji hipotesis kedua dilakukan untuk melihat peran work-family conflict terhadap intensi pindah kerja. Peneliti menggunakan metode uji regresi linear sederhana. Berdasarkan perhitungan yang dilakukan, diperoleh nilai koefisien determinasi $\mathrm{R}^{2}=0,138$. Hal ini menunjukkan bahwa work-family conflict memberikan sumbangan sebesar $13,8 \%$ terhadap intensi pindah kerja, sementara $86,2 \%$ sisanya dipengaruhi oleh faktor lain. Nilai $F=9,642$ dengan $\mathrm{p}<0,05$ menandakan bahwa hipotesis 2 yang menyatakan "terdapat peran work-family conflict terhadap intensi pindah kerja" diterima, sehingga dapat dikatakan work-family conflict berperan langsung terhadap intensi pindah kerja. Selain itu, work-family conflict juga diketahui memiliki peran positif yang signifikan terhadap intensi pindah kerja $(B=0,372, \mathrm{p}<$ $0,05)$. Arah hubungan yang bersifat positif menandakan bahwa makin tinggi nilai work-family conflict, maka makin tinggi pula nilai intensi pindah kerja atau niat individu untuk pindah dari pekerjaan tempat bekerja saat ini, dan begitu pula sebaliknya.

Jika dilihat dari peranan dimensi work-family conflict terhadap intensi pindah kerja, pengaruh yang paling besar adalah dimensi strain dengan nilai $\mathrm{R}^{2}=0,140$. Hal ini menggambarkan bahwa dimensi strain pada work-family conflict memberi pengaruh positif sebesar $14 \%$ secara signifikan terhadap intensi pindah kerja $(B=0,374, p=<0,05)$. Dimensi yang paling kecil pengaruhnya adalah time dengan nilai $R^{2}=0,080$. Hal ini menggambarkan bahwa dimensi time pada work-family conflict memberi pengaruh positif sebesar $8 \%$ secara signifikan terhadap intensi pindah kerja $(\beta=0,283, p=<0,05)$. Data selengkapnya dapat dilihat pada Tabel 7.

Tabel 7. Gambaran Peran Dimensi Work-Family Conflict terhadap Intensi Pindah Kerja

\begin{tabular}{lcccc}
\multicolumn{1}{c}{ Variabel/Dimensi } & $\mathrm{R}^{2}$ & $\mathrm{~F}$ & $\beta$ & Sig. \\
\hline Time & 0,080 & 5,225 & 0,283 & 0,026 \\
Strain & 0,140 & 9,770 & 0,374 & 0,003 \\
Behavior & 0,099 & 6,606 & 0,315 & 0,013 \\
\hline
\end{tabular}

Faktor individu, yaitu work-family conflict, dalam hal ini terbukti memiliki peran terhadap intensi pindah kerja. Hasil ini sejalan dengan beberapa penelitian sebelumnya. Alimbuto \& Rostiana (2017) yang 
meneliti 81 karyawan di Tangerang menemukan bahwa work-family conflict berhubungan positif terhadap intensi keluar kerja $\left(\mathrm{R}^{2}=0,221 ; \mathrm{p}<0,01\right)$. Begitu pula dengan penelitian yang dilakukan Nisa \& Malik (2016) terhadap 300 tenaga medis di perusahaan swasta yang menunjukkan bahwa work-family conflict berpengaruh terhadap intensi pindah kerja (CR 3,045 > 1,96; $\mathrm{p}<0,05)$. Hal ini juga senada dengan penelitian Wulandari \& Adnyani (2016) yang melibatkan 77 karyawan hotel Grand Inna Kuta, di mana diketahui bahwa terdapat pengaruh positif yang signifikan antara work-family conflict terhadap intensi keluar kerja $\left(\mathrm{R}^{2}=0,600 ; \mathrm{p}<0,01\right)$.

Uji hipotesis ketiga dilakukan untuk melihat peran persepsi peluang kerja terhadap intensi pindah kerja. Peneliti menggunakan metode uji regresi linear sederhana. Berdasarkan perhitungan yang dilakukan, diperoleh nilai koefisien determinasi $\mathrm{R}^{2}=0,233$. Hal ini menggambarkan bahwa persepsi peluang kerja memberikan sumbangan sebesar $23,3 \%$ terhadap intensi pindah kerja, sementara $76,7 \%$ sisanya dipengaruhi oleh faktor lain. Nilai $F=18,265$ dengan $\mathrm{p}<0,05$ menandakan bahwa hipotesis 3 yang menyatakan "terdapat peran persepsi peluang kerja terhadap intensi pindah kerja" diterima, sehingga dapat dikatakan bahwa persepsi peluang kerja berperan langsung terhadap intensi pindah kerja. Selain itu, diketahui pula bahwa persepsi peluang kerja memiliki peran yang signifikan terhadap intensi pindah kerja $(\beta=0,483 ; p<0,05)$. Arah hubungan yang bersifat positif menandakan bahwa makin tinggi nilai persepsi peluang kerja, maka makin tinggi pula nilai intensi pindah kerja atau niat individu untuk pindah dari pekerjaan tempat bekerja saat ini, dan begitu pula sebaliknya.

Tabel 8. Gambaran Peran Persepsi Peluang Kerja terhadap Intensi Pindah Kerja

\begin{tabular}{ccccc}
\hline Variabel & $\mathrm{R}^{2}$ & $\mathrm{~F}$ & $\beta$ & Sig. \\
\hline Persepsi peluang kerja & 0,233 & 18,265 & 0,483 & 0,000 \\
\hline
\end{tabular}

Faktor eksternal, yaitu persepsi peluang kerja, dalam hal ini terbukti memiliki peran terhadap intensi pindah kerja. Hasil ini sejalan dengan penelitian dari Victoria, Zamralita, \& Saraswati (2017) terhadap 300 karyawan perusahaan swasta yang menunjukkan bahwa terdapat hubungan antara persepsi peluang kerja terhadap intensi keluar kerja pada karyawan $\left(R^{2}=0,300 ; p<0,05\right)$. Hal ini pun senada dengan penelitian Treureun (2013) yang menyatakan bahwa adanya hubungan positif secara signifikan antara persepsi peluang kerja dengan intensi keluar kerja, hanya saja dengan peranan yang berbeda. Treuren (2013) melakukan pengambilan data dalam dua periode waktu tertentu sehingga menunjukkan peran yang lebih besar terhadap intensi keluar kerja.

Uji hipotesis keempat dilakukan untuk melihat peran kualitas kehidupan kerja, work-family conflict, dan persepsi peluang kerja terhadap intensi pindah kerja. Peneliti menggunakan metode uji regresi linear sederhana. Uji hipotesis dapat dilihat pada Tabel 9.

Tabel 9. Peran Kualitas Kehidupan Kerja, Work-Family Conflict, dan Persepsi Peluang Kerja terhadap Intensi Pindah Kerja

\begin{tabular}{lcc}
\hline \multicolumn{1}{c}{ Variabel } & $\mathrm{R}^{2}$ & $\mathrm{~F}$ \\
\hline $\begin{array}{l}\text { Kualitas kehidupan kerja, work-family conflict, dan persepsi } \\
\text { peluang kerja - Intensi pindah kerja }\end{array}$ & 0,391 & 12,411 \\
\hline
\end{tabular}

Berdasarkan tabel di atas, variabel kualitas kehidupan kerja, work-family conflict, persepsi peluang kerja memberikan sumbangan sebesar 39,1\% terhadap intensi pindah kerja, sementara $60,9 \%$ sisanya dipengaruhi oleh faktor lain. Nilai $F=12,411$ dengan $p<0,05$ menandakan bahwa hipotesis 4 yang menyatakan "terdapat peran kualitas kehidupan kerja, work-family conflict, dan persepsi peluang kerja terhadap intensi pindah kerja" diterima, sehingga dapat dikatakan bahwa kualitas kehidupan kerja, workfamily conflict, dan persepsi peluang kerja berperan langsung terhadap intensi pindah kerja.

Penelitian terhadap karyawan PT. X bidang jasa konstruksi di Jakarta Barat memperoleh hasil yang menunjukkan bahwa faktor organisasi, yaitu kualitas kehidupan kerja, memiliki pengaruh yang lebih besar dengan $\mathrm{R}^{2}=0,297$ dibandingkan faktor individu, yaitu work-family conflict, dengan $\mathrm{R}^{2}=0,138$ dan faktor eksternal, yaitu persepsi peluang kerja, dengan $\mathrm{R}^{2}=0,233$. Hasil ini berbeda dengan penelitian Wahyuni, Zaika, \& Anwar (2014) yang melibatkan 102 karyawan di perusahaan konstruksi, hasil tersebut menunjukkan bahwa faktor yang paling eksternal seperti gaji, insentif, dan sikap atasan memiliki nilai 
pengaruh paling besar dengan nilai $\mathrm{R}^{2}=0,674$ di dalamnya terdiri dari faktor komitmen dengan nilai $\mathrm{R}^{2}=$ 0,577 dan faktor internal nilai $R^{2}=0,472$. Hal ini menunjukkan bahwa ketiga variabel memiliki peran yang paling besar terhadap intensi pindah kerja karyawan dibandingkan dengan peran dari masing-masing variabel.

\section{SIMPULAN}

Kesimpulan penelitian ini adalah terdapat peran antara kualitas kehidupan kerja, work-family conflict, dan persepsi peluang kerja terhadap intensitas pindah kerja karyawan PT. X. Karyawan PT. X memiliki intensi pindah kerja yang rendah, yang berarti rata-rata partisipan penelitian di PT. X saat ini belum memiliki keinginan untuk pindah kerja. Kualitas kehidupan kerja karyawan PT. X tergolong tinggi. Hal ini menunjukkan bahwa perusahaan sudah cukup memberikan dukungan kepada karyawan, tidak hanya di tempat kerja, namun juga pada kehidupan di luar pekerjaan. Work-family conflict karyawan PT. X tergolong rendah, yang menunjukkan bahwa karyawan PT. X masih bisa mengatur peran tanggung jawabnya sebagai karyawan maupun anggota keluarga dalam kehidupannya. Persepsi peluang kerja karyawan PT. X tergolong tinggi, artinya karyawan PT. X menilai adanya alternatif penawaran pada pasar tenaga kerja di luar organisasi saat ini.

Kualitas kehidupan kerja berperan negatif secara signifikan terhadap intensi pindah kerja pada karyawan PT. X. Dengan demikian, makin tinggi nilai kualitas kehidupan kerja, maka makin rendah intensi pindah kerja, dan begitu pula sebaliknya. Work-family conflict memiliki peran positif yang signifikan terhadap intensi pindah kerja pada karyawan PT. X. Dengan demikian, makin tinggi nilai work-family conflict, maka makin tinggi pula intensi pindah kerja, dan begitu pula sebaliknya. Persepsi peluang kerja memiliki peran positif terhadap intensi pindah kerja pada karyawan PT. X. Dengan demikian, makin tinggi nilai persepsi peluang kerja, maka makin tinggi pula nilai intensi pindah kerja, dan begitu pula sebaliknya. Peran kualitas kehidupan kerja, work-family conflict, dan persepsi peluang kerja secara bersama-sama memiliki pengaruh terhadap intensi pindah kerja. Dengan kata lain, pendekatan komprehensif perlu dilakukan karena bersama-sama menelaah dari faktor organisasi, individu, dan eksternal.

Penelitian ini tidak terlepas dari keterbatasan. Jumlah partisipan yang hanya 62 orang tergolong kecil sehingga tidak dapat digeneralisasi terhadap orang pada umumnya. Sebaiknya, penelitian selanjutnya melibatkan partisipan dengan jumlah yang lebih banyak agar hasil penelitian dapat digeneralisasi secara lebih baik. Partisipan bisa diperoleh dari berbagai bidang industri perusahaan agar dapat melihat gambaran perbedaan setiap perusahaan dalam menyikapi intensi pindah kerja karyawannya.

Hasil penelitian menunjukkan adanya peran kualitas kehidupan kerja, work-family conflict, dan persepsi peluang kerja terhadap intensi pindah kerja dengan nilai $\mathrm{R}^{2}=0,391$ yang tidak melebihi $40 \%$, sehingga masih terdapat $60 \%$ hal yang memengaruhi intensi pindah kerja pada partisipan penelitian oleh variabel lain yang tidak diteliti dalam penelitian. Peneliti menyarankan agar penelitian selanjutnya mencoba model penelitian lain dan melakukan studi agar lebih menggambarkan variabel yang mungkin berperan terhadap intensi pindah kerja.

Berdasarkan temuan penelitian ini, kualitas kehidupan kerja memiliki hubungan negatif dengan intensi pindah kerja. Dengan demikian, PT. X harus lebih memperhatikan dimensi-dimensi kualitas kehidupan kerja yang masih dinilai kurang. PT. X dapat memperbaiki kualitas kehidupan kerja di perusahaan agar karyawan lebih puas terhadap perusahaan dan pekerjaannya sehingga karyawan tidak berpikir unutk pindah kerja.

Adapun saran bagi perusahaan dapat ditinjau dengan melihat tiga aspek utama yang memiliki pengaruh paling tinggi terhadap intensi pindah kerja, yaitu job characteristic, promotion, dan personal development. Dari aspek job characteristic terkait kejelasan kerja, dapat dilakukan penyusunan key performance indicator (KPI) dari setiap terutama bagian penjualan dan proyek agar setiap karyawan mengetahui tugas dan perannya. Dari segi promotion yang berkaitan dengan kejelasan mekanisme peningkatan karir, perusahaan dapat membuatkan jenjang karier yang jelas dan evaluasi kinerja secara rutin terhadap karyawan. Dari segi personal development terkait peluang mengikuti pelatihan, perusahaan dapat 
memberikan pelatihan yang dibutuhkan oleh masing-masing karyawan sesuai dengan kebutuhan yang harus ditingkatkan untuk mendukung pekerjaan dan menambah keahlian karyawan.

Adapun saran kepada karyawan PT. X, meskipun nilai dimensi promotion pada PT. X tergolong kurang, karyawan dapat mengembangkan dirinya agar dapat diberi kesempatan dan peluang promosi dari perusahaan. Karyawan dapat mengikuti pelatihan ataupun seminar dan berdiskusi dengan komunitas profesional sesuai dengan bidangnya untuk menambah pengetahuan dan keterampilan diri agar mendapat peluang promosi dari perusahaan.

\section{DAFTAR PUSTAKA}

Alimbuto, S., \& Rostiana (2017). Peran konflik pekerjaan-keluarga terhadap intensi pindah kerja dengan persepsi dukungan organisasi sebagai moderator. Jurnal Muara Ilmu Sosial, Humaniora, dan Seni, $1(2), 48-54$

Alony, I., Hasan, H., \& Sense, A. (2014). Predicting Turnover Based on Relationship Diagnosis - Lessons from Marital Research. Proceedings of Informing Science \& IT Education Conference, 25-37.

Afsar, B., \& Rehman, Z. U. (2017). Relationship between Work-Family Conflict, Job Embeddedness, Workplace Flexibility, and Turnover Intentions. Makara Human Behavior Studies In Asia, 21(2), 92104.

Giffen, R. (2015). Organizational culture and personality type: Relationship with person-organization fit and turnover intention. Iowa State University.

Karunanayake, D. R. N. S. K., \& Weligamage, S. S. (2016). Effects of quality of work-life on turnover intention: Evidence from sewing machine operators in Sri Lanka apparel industry. Kelaniya Journal of Human Resource Management, 11(2), 59-73.

Kumar, B. R., \& Thomas, B. (2016). An empirical study on perceived quality of work life and turnover intention among the employees of private hospitals. International Journal of Latest Trend in Engineering and Technology, 511-519.

Lu, Y., Hu, X. M., Huang, X. L., Zhuang, X. D., Guo, P., Feng, L. F., Hu, W., Chen, L., Zou, H., \& Hao, Y. T. (2017). The relationship between job satisfaction, work stress, work-family conflict, and turnover intention among physicians in Guangdong, China: A cross-sectional study. BMJ Open, 7(5).

Mosadeghrad, A. M. (2013). Quality of working life and turnover intentions: Implications for nursing management. International Journal of Research in Nursing, 4(2), 47-54.

Nisa, N. H. \& Malik, N. (2016). Pengaruh work overload dan work family conflict terhadap turnover intention yang dimediasi oleh work exhaustion. Journal of Innovation in Business \& Economics, 7(1), $67-76$.

Pratiwi, V. R. \& Riyono. B. (2017). Peran ketidakpuasan kerja terhadap intensi turnover karyawan dengan stabilitas anchor sebagai moderator. Gadjah Mada Journal of Psychology, 3(1), 45-58.

Rostiana, Zamralita, \& Suyasa, P. T. Y. S. (2014). Alat ukur quality of work-life. Universitas Tarumanagara.

Rostiana, Zamralita, \& Suyasa, P. T. Y. S. (2014). Alat ukur turnover intention. Universitas Tarumanagara.

Rostiana, Zamralita, \& Suyasa, P. T. Y. S. (2016). Alat ukur work family conflict. Universitas Tarumanagara.

Swamy, D. R., Nanjundeswaraswamy, T. S., Rashmi, S. (2015). Quality of work life: Scale development and validation. International Journal of Caring Sciences, 8(2), 281-300.

Slavianska, V. (2012). Measuring the impact of human resource management practices on employee turnover. Problems of Management in the $21^{\text {st }}$ Century, 4(64), 63-73.

Treuren, G. (2013). The relationship between perceived job alternatives, employee attitudes and leaving intention. Anzam, 1-18.

Victoria, Y., Zamralita, \& Saraswati, K. D. H. (2017). Peran kualitas kehidupan kerja dan persepsi peluang kerja terhadap intensi pindah kerja. Jurnal Muara Ilmu Sosial, Humaniora, dan Seni, 1(2), 326-335. 
Wahyuni, A. S., Zaika, Y., \& Anwar, R. (2015). Analisis faktor-faktor yang mempengaruhi turnover intention (keinginan berpindah) karyawan pada perusahaan jasa konstruksi. Jurnal Rekayasa Sipil, $8(2), 89-95$.

Wulandari, I. A. D., \& Adnyani, I. G. A. D. (2016). Pengaruh work family conflict terhadap turnover intention melalui mediasi kepuasan kerja pada Hotel Grand Inna Kuta. E-Jurnal Manajemen Unud, 5(10), 813-839. 